\title{
COMPREENDENDO O FRACASSO ESCOLAR COMO UMA PRODUÇÃO HISTÓRICA E SOCIAL
}

Resenha da obra: Patto, M. H. S. (2015). A produção do fracasso escolar: histórias de submissão e rebeldia ( $4^{a}$ ed). São Paulo: Casa do Psicólogo

\author{
Kairon Pereira de Araújo Sousa \\ Jefferson Machado Nobrega \\ Universidade Federal do Piauí \\ Renata Miranda de Freitas \\ Universidade Estadual do Piauí
}

O livro A produção do fracasso escolar: histórias de submissão e rebeldia, escrito pela psicóloga e doutora em Psicologia Escolar e do Desenvolvimento Humano pela Universidade de São Paulo (USP), Maria Helena Souza Patto, reeditado (4 ${ }^{\text {a }}$ edição revista e ampliada) pela Editora Intermeios, foi lançado pela primeira vez em 1990. A obra produziu grande impacto nas discussões sobre o tema, suscitando interesse e servindo de referência para pesquisadores em educação, psicólogos escolares, professores, diretores, entre outros. Na presente obra, Patto desenvolve reflexões conceituais importantes que nos ajudam a compreender o fracasso escolar sob outra perspectiva.

Pensar o insucesso escolar como produzido unicamente pelo sujeito ou como sendo consequência do contexto sociocultural em que ele se insere, atribuindo-lhe, acriticamente, a responsabilidade em relação a um fenômeno psicossocial de natureza complexa (fracasso escolar), significa subverte a ordem das coisas, recorrendo a subterfúgios ideológicos e reducionistas para legitimar as desigualdades no âmbito social.

Embora tenha sido identificada a existência de outras resenhas acerca do livro, cabe salientar que estas são majoritariamente trabalhos de graduandos, realizados em disciplinas durante a graduação, não sendo publicadas em periódicos. Ademais, a resenha que tem sido reconhecidamente apreciada, uma vez que foi lançada em revista científica (Revista Brasileira de Estudos Pedagógicos, $\mathrm{n}^{\circ}$ 72, v. 171 , pp. 215-217, maio/ago. 1991) data da década de 90 (referente à $1^{\text {a }}$ edição do livro), cuja autora é Maria das Graças de Castro Senna, que na publicação aparece vinculada à Universidade Federal de Minas Gerais (UFMG). Não obstante, convém 
ressaltar que o livro, face à grande aceitação no meio acadêmico, gerou novas edições. A versão vigente ( $4^{a}$ edição) apresenta um dossiê "25 anos depois", assim, além de fazer o percurso de análise crítica dos capítulos da obra, tem como novidade uma pesquisa de campo que mostra a vida presente das quatros crianças acompanhadas por Maria Helena Souza Patto, no estudo original. Além deste capítulo, que gera curiosidade ao leitor em relação ao rumo de vida desses personagens, é apresentado outro que versa sobre a trajetória desse clássico, bem como um posfácio da autora. Assim, considerando trata-se de um manuscrito revisado e ampliado, pensa-se ser relevante a realização dessa resenha que objetiva recolocar novamente o publico leitor em contato com o livro, mais de vinte cinco anos depois de seu primeiro lançamento. Feito esse preambulo, nas linhas a seguir, procura-se sintetizar os principais pontos da obra, apresentando-se ao final uma breve consideração.

No referido manuscrito, Maria Helena Souza Patto apresenta ao público sua pesquisa sobre o fracasso escolar das crianças pobres de um bairro periférico na cidade de São Paulo. Insatisfeita com os altos índices de reprovação e evasão escolar na escola pública de primeiro grau, recorrente ao longo dos anos, inclusive no início da década de 80, e com as extensas explicações parciais, enviesadas por preconceitos e estereótipos, fornecidas pela literatura na tentativa de justificar as causas do fracasso escolar nesse âmbito educacional, Patto decide estudar com mais afinco o fenômeno, indo às suas raízes, oferecendo uma forma alternativa de compreensão da problemática.

A obra se estrutura em duas partes. Na primeira, a autora realiza uma revisão crítica da literatura sobre a temática, identificando as concepções e discursos teóricos produzidos para explicar as causas do fracasso escolar em escolares do ensino público do primeiro grau. $\mathrm{Na}$ outra parte (segunda), Patto se dedica à análise dos dados coletados na pesquisa de campo, obtidos através de observações e entrevistas com diferentes atores, nos espaços da escola, nas ruas do bairro e residências das famílias acompanhadas durante o estudo.

Revisando a literatura disponível acerca do fracasso escolar (a primeira tarefa), Patto se surpreende com as explicações unilaterais marcadas por forte preconceito utilizadas para explicar as causas desse fenômeno. Reflexo de uma sociedade capitalista, sedimentada em classes sociais e em estruturas de poder 
hierarquicamente estabelecidas, esses discursos são difundidos, enunciando a visão de mundo que perpassa essas diferentes teorias, como constata a autora.

Patto discute como a reprodução das teorias e/ou ideias europeias na descrição das características dos sujeitos ganha espaço entre os escritores brasileiros, servindo mais para naturalizar as desigualdades sociais, do que para elucidar o problema do fracasso escolar. Uma destas ideologias, compatibilizada pelo meio intelectual do país, foi a Teoria das Raças, na qual as desigualdades sociais são justificadas a partir de termos raciais.

Tendo isso em conta, os povos miscigenados são identificados como seres incapazes. Essa tese, como mostra a autora, repercute no Brasil, ganhando contornos que chegam a ultrapassar o limite da racionalidade. Na confluência do pessimismo, Sílvio Romero, um dos representativos intelectuais da época, absorvido por essa crença, chega a propor o branqueamento gradual da população através de sucessivas migrações, o que resultaria, na sua visão, no progresso do país.

Nesse itinerário histórico, também se identificam explicações pautadas no Darwinismo Social que postula a seletividade natural no meio prevalecendo os mais aptos, daí a recorrência ao mito das chamadas aptidões individuais. Outra ideologia, recorrente, foi a Teoria da Carência Cultural que aponta o fracasso escolar como resultado da carência do meio sociocultural de crianças pobres. Além destas, as explicações sobre a reprovação e evasão escolar com base em fatores genéticos e teorias médicas (higiene mental-correção dos desvios) também ecoaram nas publicações sobre o tema. Em todas elas, como observa Patto, as crianças carentes aparecem como sendo o centro da problemática, ora como integrantes de um sistema familiar marginal que não lhes oferece as estimulações ou a cultura necessária para um bom rendimento escolar, ora como o locus da patologização.

Embora tenha localizado algumas rupturas em relação a estas ideias estereotipadas em manuscritos que analisou (como o de Caio Prato), Patto no geral conclui que: "no período de quase um século, portanto, mudam as palavras, permanece uma explicação: as crianças pobres não conseguem aprender na escola por conta de suas deficiências sejam elas de natureza biológica, psíquica ou cultural" (Patto, 2015, p. 159).

Com o intuito de contribuir de forma crítica para o entendimento do fracasso escolar, Patto adota como pressupostos epistemológicos: o materialismo histórico dialético (Carl Marx) e o conceito sociológico de vida cotidiana (Agnes 
Heller). Partindo destes aportes teóricos, a autora demonstra como as relações de poder, cristalizadas no cotidiano dos espaços escolares e sociais, influenciavam as práticas pedagógicas. É por esse percurso que a ela consegue desconstruir os mitos, preconceitos e ideologias cientificamente legitimadas que enviesam o processo educativo, culpabilizando o sujeito e a sua história de vida pelo fracasso escolar. Sendo assim, aborda o fenômeno como uma construção histórica e social.

Concluída a primeira tarefa (revisão da literatura), Patto vai a campo, "permanecemos numa escola pública de primeiro grau e num bairro da periferia da cidade de São Paulo, onde foram realizadas observações em vários contextos e entrevistas formais e informais com todos os envolvidos no processo educativo [...]" (Patto, 2015, p. 29).

Foi analisando o cotidiano escolar e as relações sociais em seu entorno (espaços extraescolares), a partir do acompanhamento de quatro crianças repetentes (Ângela, Augusto, Nailton e Humberto), que a pesquisadora identificou como os discursos ideológicos presentes na literatura se operacionalizavam na vida real, afetando o processo de ensino-aprendizagem. As relações de poder e dominação perpassavam o espaço escolar representando o retrato de um macrossistema verticalizado. Isso ficou perceptível, conforme observa Patto, através do modo como se desenvolvia as relações entre diretoria, esquipe pedagógica, professores e alunos. Frente ao fracasso escolar, a responsabilização tinha via única, resvalando, no final, sempre no aluno e na sua família.

Considerando a história de vida das crianças (sentenciadas ao fracasso escolar), a autora mencionou como foram construídas as estratégias ou artimanhas do poder que visavam ocultar as raízes do problema, para tanto não bastava apenas enunciar era preciso fazer crer. Assim, ideologicamente, as famílias e crianças foram convencidas de que o problema da reprovação ou da falta de aprendizagem era provocado unicamente por eles. Ao entrevistar os pais de quatro crianças multirrepetentes, Patto identificou a reprodução desta ideologia nos discursos, como, por exemplo, na fala da Sr. ${ }^{a}$ Cícera, mãe de Ângela -aluna da escola onde ocorreu o estudo: "não sei se ela é muito esperta, não sei se tem boa memoria" (Patto, 2015, p. 314).

As violências simbólicas, físicas e verbais eram constantes nas salas de aulas, como constatou a pesquisadora. Tendo como fundamento os mitos difundidos por pseudoteorias, as professoras, arbitrariamente, reproduziam a violência, 
classificando, discriminando e patologizando as crianças. O hábito de falar mal dos alunos, focalizando apenas as vulnerabilidades, esquivando-se das potencialidades inerentes a cada indivíduo, refletia, de acordo com Patto, o grau de alienação das docentes.

A partir da análise minuciosa da literatura e da pesquisa em campo, Patto formulou algumas conclusões, finalizando a segunda parte do livro: (1) as teorias sobre o fracasso escolar que enfatizam o déficit e as diferenças culturais carecem de revisão, devendo levar em contar os mecanismos escolares que produzem as dificuldades de aprendizagem; (2) o fracasso escolar da escola pública de primeiro grau resulta de um sistema educativo que produz obstáculos à concretização de seus objetivos; (3) o fracasso escolar é legitimado e mantido através de um discurso científico naturalizador desse processo; e (4) a relação entre mecanismos neutralizadores de conflitos e manifestações torna a escola um lugar apropriado à passagem ao compromisso humano-genético.

Exposto os principais pontos presentes nas duas partes que compõe a obra no formato original, em seguida apresenta-se uma síntese dos textos extras que aparecem na quarta edição do livro, agrupados na parte "25 anos depois".

No texto de abertura, José Sérgio $F$. de Carvalho reflete sobre $A$ produção do fracasso escolar: a trajetória de um clássico. Nele, o autor mostra como a obra de Maria Helena Souza Patto foi se consolidando nos diversos espaços sociais, atingindo e mantendo ao longo dos anos um reconhecimento, que a tornou obra obrigatória em cursos de graduação, pós-graduação, etc., transformando-se em um trabalho de grande popularidade no meio acadêmico. O que explicaria tal feito? De acordo com Carvalho, uma hipótese plausível é a de que o livro não é meramente mais um manuscrito lançado em meio a um mercado volátil de ideias do campo da educação, mas um clássico. Ademais, o autor ressalta o aspecto de ruptura teóricometodológica e o acesso à cotidianidade das relações na instituição escolar e seu entorno social, realizados por Patto, como fatores que contribuíram para longevidade e alcance do livro.

No texto seguinte, intitulado Quatro histórias de (re)provação escolar: notas sobre os rumos das vidas de Ângela, Nailton, Augusto e Humberto, Denise Trento Rebello de Souza e Daniele Kohmoto Amaral relatam dados da pesquisa realizada por esta, tendo como orientadora aquela, para a dissertação de mestrado, cujo o intuito foi identificar os sentidos e marcas na trajetória de vida de Ângela, 
Nailton, Augusto e Humberto, após sucessivas reprovações no começo da escolarização, contribuindo, assim, para a compreensão do fracasso escolar e do processo de escolarização.

Por meio de pesquisa de campo realizada entre maio de 2007 e fevereiro de 2010, foi possível a localização de Ângela (que ainda morava na mesma residência por ocasião do primeiro estudo na década de 80 ) e Nailton. O rumo de suas vidas transparece as marcas de um processo de escolarização malsucedido. Ângela (à época da pesquisa), casada, mãe de dois filos, ainda persistia na busca do sonho de, segundo ela, "ser uma mulher inteligente", fazendo menção à busca por uma formação superior. Somente em 2004, com quase trinta anos de idade, entre interrupções e continuidade, conseguiu concluir o ensino médio. Nailton seguiu a profissão do pai: pedreiro. E como ele mesmo destaca "Ah, depois que tacha, já era", sinalizando, de acordo com as autoras, o quanto os estereótipos e rótulos afetam o sujeito, repercutindo no abandono da escola.

Por fim (posfácio), Maria Helena Souza Patto faz alguns apontamentos referentes ao estudo sobre o fracasso escolar, das suas impressões referentes ao local da pesquisa, das influencias teóricas que foram moldando sua visão sobre o fenômeno, das distorções presentes na literatura, da própria conjuntura histórica e dos desdobramentos e repercussões no campo da educação ao logo dos anos.

Nesse manuscrito, Patto promove uma ruptura na análise histórica das causas do fracasso escolar. Indo às suas raízes, traz à tona diversos fatores ocultados pelas Teorias ao longo dos anos, tratando do fracasso escolar como uma produção história e social. A partir desse livro é possível ter um panorama mais detalhado a respeito desse fenômeno, uma vez que autora não se limita a uma determinada visão de mundo, ou mesmo ao Zeitgeist de uma época. Trata-se de uma obra indispensável àqueles que pretendem estudar a psicologia escolar educacional. Deste modo, recomenda-se a leitura desse livro por estudantes, professores e pesquisadores da psicologia ou áreas afins.

\section{REFERÊNCIA}

Patto, M. H. S. (2015). A produção do fracasso escolar: histórias de submissão e rebeldia ( $4^{\mathrm{a}}$ ed). São Paulo: Casa do Psicólogo. 